\title{
Telehealth in the Developing World
}

\author{
Jung A Kim, RN, PhD
}

Department of Nursing, Hanyang University joyhippo@hanyang.ac.kr

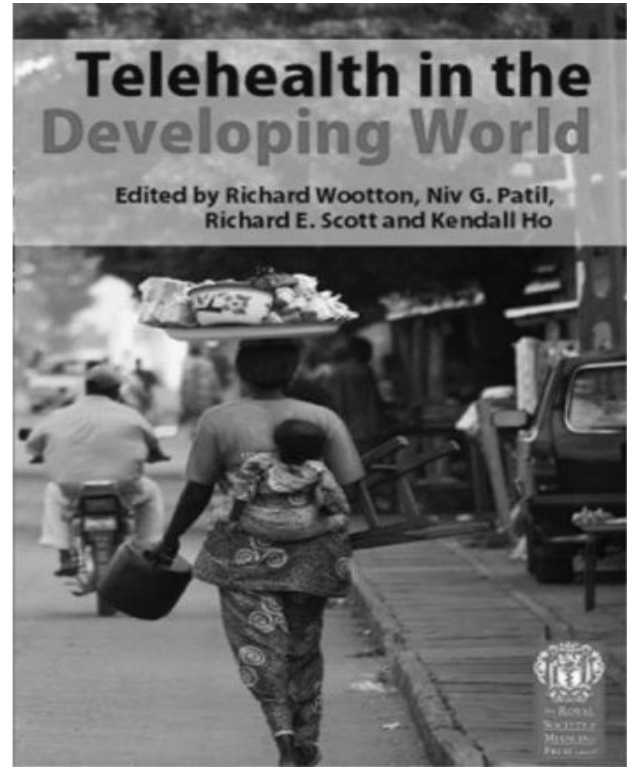

By Wootton R, Patil NG, Scott RE, and Ho K

Telehealth in the developing world

London: Royal Society of Medicine Press/IDRC; 2009

ISBN 978-1-85315-784 • ISBN e-book 978-1-55250-396-6

Paperback.318 pages $9.1 \times 6.1 \times 0.8$ inches

$\$ 58.00$ US

This is an Open Access article distributed under the terms of the Creative Commons Attribution Non-Commercial License (http://creativecommons.org/licenses/bync/3.0/) which permits unrestricted non-commercial use, distribution, and reproduction in any medium, provided the original work is properly cited.

(C) 2010 The Korean Society of Medical Informatics
Telehealth is the delivery of healthcare services and information via high-tech telecommunications technologies. While saving time, energy and money to visit a medical specialist, patients will be given more opportunities to get high-quality healthcare services. From a healthcare provider's perspective, telehealth has the benefits of improving the continuity of care, offering an opportunity of continuing education and increasing cooperation in diagnosis and research activities.

Above all, telehealth is a means of improving the limited and imbalanced medical resource supply structure that the service can be directly provided to those in poor areas or prisoners. In fact, telehealth is a concept in which the interest and care for those who want the minimum services at least to stay healthy should be considered along with the technology itself.

Many people from the developing world have suffered from limited medical resources and poor and inappropriate healthcare services. In particular, the problem was far more serious in rural and remote communities. Therefore, telehealth could be more meaningful in the developing world than advanced countries where medical resources are already abundant, and the access to high-quality healthcare services and excellent healthcare professionals is much easier.

Wootton, one of the editors of this book, pointed out that even though a lot of articles have been published on the concept of telemedicine in the developing world, a success story has been barely told. He has attempted to collect and suggest a representative cross-section of the very wide range of work that has been carried out in this book. He also mentioned that the related policies and clinical and educational matters that are covered in this book insisted that this book includes a state-of-the art review of telemedicine in the developing world and provides the base for a high-level operation manual.

In fact, various telemedicine projects and related case studies which have been performed in poor areas in the develop- 
ing world and the experiences in the process are described in this book. This book is comprised of five sections as follows:

\section{Section 1: BACKGROUND}

Introduction

\section{Section 2: POLICY}

Bridging the digital divide: linking health and ICT policy

Telehealth in developing countries: perspectives from the Philippines

Informationa technology for primary heath care in Brazil

Community-based health workers in developing countries and the role of $\mathrm{m}$-health

Global e-health policy: from concept to strategy

Experiences and lessons learnt from telemedicine projects supported by IDRC

Strategies to promote e-health and telemedicine activities in developing countries

\section{Section 3: EDUCATIONAL}

Telemedicine in low-resource settings: experience with a telemedicine service for HIV/AIDS care

Medical missions for children: a global telemedicine and teaching network

Telementoring in India: experience with endocrine surgery

\section{Section 4: CLINICAL}

Teledermatology in developing countries

Cross-cultural telemedicine via email: experience in Cambodia and the US

Telepathology and televytology in developing countires Internet based store-and forward telemedicine for subspecialty consultations in the Pacific region

Telehealth support for a global network of Italian hospitals Telemedicine in Nepal

Telemedical support for surgeons in Ecuador A low-cost international e-referral network Telehealth in China: opportunity and challenges Telemedicine in South Africa
Telemedicine in sub-Saharan Africa

Telehealth for mountainous and remote areas of northern Pakistan

Teleneurology: past, present and future

Telepaediatric support for a field hospital in Chechnya

Web-based paediatric oncology information and registries: an international perspective

e-Health in international networks: new opportunities for collaboration

\section{Section 5: THE FUTURE}

The future use of telehealth in the developing world

This book is significant in that it states the current status and success story of telehealth in the developing world and the lessons obtained in the process of carrying out the service. Furthermore, this book can be a useful resource to experts, teachers and students who are interested in providing high-quality healthcare services through telehealth technologies and in providing practical guidelines to policy makers who plan to launch the telehealth system in the developing world, and to working-level engineers and program developers.

In Korea, telehealth was first launched in 1988 between Seoul National University Hospital and Yeoncheon Public Health Center. It was a pilot project for remote video medical examination. Since then, various studies and pilot projects have been conducted in diverse sectors such as the visiting public health project, health consultation and health management in order to introduce telehealth technologies. Recently, the Korean government publicly announced the launching of 'Telehealth' which represents 'u-health-based medical care services' and 'Health Management Services' which target to keep all citizens stay healthy. For this, a bill to amend the Medical Service Act has been submitted to the National Assembly of Korea. The Korean Ministry of Health \& Welfare expects that the expansion of telehealth would bring direct benefits to those living in medically deprived areas. The numerous historical records and vivid experiences described in this book would be critical resources for Korea to take care of the problems it has recently faced with the expansion of telehealth. 